\title{
A EDUCAÇÃo AMBIENTAL COMO CRÍTICA AO DESENVOLVIMENTO SUSTENTÁVEL: NOTAS SOBRE O MÉTODO
}

\author{
Roberto Leher ${ }^{1}$
}

\begin{abstract}
Resumo
O presente artigo sistematiza preocupações de método sobre a problemática ambiental e, particularmente, sobre a educação ambiental. Defende que é possível encontrar, atualmente, duas grandes vertentes sobre a questão ambiental (às quais correspondem duas perspectivas metodológicas de concebê-las) nas quais a educação ambiental está inserida: a primeira combina culto à vida silvestre e ecocientificismo, buscando mitigar e harmonizar os efeitos do desenvolvimento para o ambiente e a sociedade; a segunda vem sendo forjada nas lutas contra as expropriações e a mercantilização de todas as formas de vida, assume a configuração de conflitos socioambientais e, em geral, possui caráter anticapitalista. Os relatórios sobre as mudanças climáticas globais, as lutas planetárias contra as expropriações, as migrações decorrentes de guerras pelo controle de recursos naturais, os conflitos urbanos advindos da prevalência dos interesses do capital nas cidades-mercadorias, corroboram que o conhecimento sobre a problemática socioambiental tenha de assumir caráter estratégico nas universidades e na sociedade em geral.
\end{abstract}

Palavras-chave: Problemática socioambiental. Educação ambiental. Universidade. Epistemologia. Movimentos sociais.

\begin{abstract}
This article explores concerns of method about environmental issues and especially on environmental education. It argues that it is possible to find currently two major aspects of the environmental issue (to which correspond two methodological perspectives to conceive them) in which environmental education is inserted: the first combines cult of wildlife and ecoscientificism, seeking to mitigate and harmonize the effects of development on the environment and society; the second has been forged in the struggles against the expropriations and the commodification of all life forms, it takes the configuration of social and environmental conflicts, and in general, has an anti-capitalist character. The reports on global climate change, planetary struggles against expropriations, migration due to wars for control of natural resources, urban conflicts arising from the prevalence of the interests of capital in the mega-events cities corroborate that knowledge about social and environmental issues has to take strategic character in the universities and in the society in general.
\end{abstract}

Keywords: Environmental problematic. Environmental education. University. Epistemology. Social movements.

\section{Resumen}

Este artículo sistematiza la preocupaciones del método por las problemáticas ambientales y en particular por la educación ambiental. Sostiene que es posible encontrar en la actualidad dos aspectos principales de la cuestión ambiental (que corresponden a dos perspectivas metodológicas a concebir) en el que se inserta la educación ambiental: la primera combina culto de la vida silvestre y eco-cientificismo, tratando de mitigar y armonizar los efectos del

\footnotetext{
${ }^{1}$ Professor Titular da Faculdade de Educação da Universidade Federal do Rio de Janeiro, pesquisador do CNPq, Cientista de Nosso Estado FAPERJ, colaborador da Escola Nacional Florestan Fernandes. Atualmente é reitor da UFRJ.
} 
desarrollo sobre el medio ambiente y la sociedad; la segunda se ha forjado en las luchas contra las expropiaciones y la mercantilización de todas las formas de vida, toma la configuración de los conflictos sociales y medioambientales, y, en general, tiene carácter anticapitalista. Los informes sobre el cambio climático global, las luchas planetarias contra expropiaciones, las migraciones debido a las guerras por el control de los recursos naturales, los conflictos urbanos derivados de la prevalencia de los intereses del capital en las ciudadesmercancías corroboran que el conocimiento acerca de los problemas sociales y medioambientales tiene que tomar carácter estratégico en las universidades y en la sociedad en general.

Palabras clave: Problemática socio-ambiental. Educación ambiental. Universidad. Epistemología. Movimientos sociales.

\section{Introdução}

Os relatórios sobre as mudanças climáticas globais, as lutas planetárias contra as expropriações, as migrações decorrentes de guerras pelo controle de recursos naturais, os conflitos urbanos advindos da prevalência dos interesses do capital nas cidades-mercadorias, tudo isso corrobora que o conhecimento sobre a problemática socioambiental tenha de assumir caráter estratégico nas universidades e na sociedade em geral. $\mathrm{O}$ presente artigo pontua algumas preocupações de método sobre o tema. Embora a generalização possa ser arriscada e abusiva, é possível encontrar, atualmente, duas grandes vertentes sobre a questão ambiental (às quais correspondem duas perspectivas metodológicas de concebê-las) nas quais a educação ambiental está inserida: a primeira combina culto à vida silvestre $\mathrm{e}$ ecocientificismo, buscando mitigar e harmonizar os efeitos do desenvolvimento para o ambiente e a sociedade; a segunda vem sendo forjada nas lutas contra as expropriações e a mercantilização de todas as formas de vida, assume a configuração de conflitos socioambientais e, em geral, possui caráter anticapitalista.

\section{A vertente pró-sistêmica e o Estado gerenciador do ambiente}

A vertente mais conhecida e de maior repercussão nas políticas de Estado é herdeira das conferências mundiais - e metodologicamente é elaborada a partir dessas formulações como as de Tbilisi, cidade localizada na extinta URSS, em que foi realizada a Primeira Conferência Intergovernamental sobre Educação Ambiental (1977), à qual se seguiram várias outras, com alcances diversos, organizadas em torno da UNESCO, PNUD e Banco Mundial. Seus documentos foram sendo incorporados por diversos Estados, por intermédio de leis de distintos alcances (constitucionais, ordinárias) e por regulamentações mais frágeis, como decretos e portarias que aprisionam a problemática ambiental nos marcos do modo de produção capitalista.

A generosa produção de documentos, legislações, resoluções internacionais e regulamentações estatais têm influenciado muitos estudos e pesquisas que, em geral, partem de um histórico da evolução dessas conferências, comparam estas com as legislações nacionais e realizam a exegese de suas próprias legislações. O problema desse método é tomar os organismos internacionais e os Estados como entes autônomos, os verdadeiros campos de disputa, como se a compreensão das normas, leis e resoluções equivalessem à totalidade do mundo real. Muitas vezes, as disputas internas nos organismos internacionais e nos Estados são concebidas como se fossem os embates essenciais, desconsiderando o alerta de Engels quando afirma que a sociedade civil é o elemento determinante e o Estado o elemento determinado. 
Marx não só tinha chegado à mesma perspectiva como também já nos DeutschFranzösische Jahrbücher (1844) havia a partir daí generalizado que, em geral, não é o Estado que condiciona e rege a sociedade civil [bürgerlicheGesellschaft], mas é a sociedade civil que [condiciona e rege] o Estado, que, por conseguinte, há que explicar a política e a sua história a partir das relações económicas e do seu desenvolvimento, e não inversamente (ENGELS, 1885, apud BARATA-MOURA et al., 1982, p.199).

Assim, essa forma de conceber a constituição da problemática socioambiental não corresponde às situações concretas, pois se exime de analisar a anatomia da sociedade civil: a economia política. As relações econômicas - e as classes que as movem - são os determinantes da questão. O Brasil possui uma legislação ambiental considerada avançada, mas, ao mesmo tempo, aprofunda o modelo neoextrativista, faz uso intensivo de energia e disponibiliza preciosos recursos hídricos para corporações que atuam na produção de celulose, soja, minérios etc. Grande parte desses setores econômicos se vale de relações de trabalho brutais, sendo a área de maior concentração de trabalho análogo a escravidão e de trabalho de crianças. A catástrofe decorrente do rompimento da barragem da Samarco, em 5 de novembro de 2015, em Mariana, Minas Gerais, o maior crime socioambiental do país e o maior desastre decorrente de rompimento de barragem do mundo, colocou em evidência as entranhas do modelo extrativista: nenhum respeito aos moradores da região, ao meio ambiente, ao uso da água e desconcertante inação de um Estado que possui sofisticada legislação ambiental.

Distintamente do apregoado pelo modelo discursivo da mineração responsável, sustentável, referenciada no controle tecnológico dos processos extrativos, a tragédia revelou a completa desconsideração aos avanços tecnológicos consagrados no tratamento dos minérios, no reuso dos resíduos, na engenharia de barragens, na avaliação diagnóstica e na governança das barragens no Brasil. Muitos poderiam argumentar que se tratava de uma empresa atrasada tecnologicamente; entretanto, é preciso lembrar que a Samarco é uma joint venture de duas corporações mundiais: Vale S.A. e da BHP Billiton, cada uma com $50 \%$ de seu capital. O crime socioambiental explica, de modo rude, a prevalência dos interesses das corporações no processo de tramitação do novo código de mineração, como é possível depreender do projeto de lei 5807/13 (BRASIL, 2013), na lei das barragens, Lei 12.334/2010 (BRASIL, 2010) e a ausência de políticas para que os royalties - quase que inexistentes, em virtude da liberalização da atividade mineradora desde a ditadura empresarial-militar financiem alternativas econômicas que possibilitem o bem-viver dos povos.

Os recentes retrocessos na legislação ambiental brasileira, como o novo código florestal (Lei 12.651/2012) (BRASIL, 2012), não podem ser compreendidos fora dos estudos sobre como determinadas frações burguesas operam o modelo extrativista. O mesmo ocorre, grosso modo, na América Latina, região em que a legislação ambiental já se encontra bastante desenvolvida, mas na qual os setores dominantes encontram-se firmemente engajados no rústico extrativismo de novo tipo.

A opção por um método que converte o Estado em unidade de análise bastante em si inevitavelmente leva à reiteração da ordem e ao reforço da institucionalidade vigente. Muitos estudos e pesquisas, ao focalizarem a análise interna desses documentos, concluem que existe uma polarização nas concepções sobre a problemática ambiental, como se houvesse um corte epistemológico entre o culto à vida silvestre e o ecocientificismo. A rigor, os dois enfoques possuem pressupostos comuns, conforme argumento adiante, ao examinar o Instituto 
Brasileiro do Meio Ambiente e dos Recursos Naturais Renováveis - IBAMA. Antes de seguir a análise, uma rápida explicitação dos termos é necessária ${ }^{2}$.

(i) Culto à vida silvestre, orientação que busca se referenciar na ecologia - políticas que em geral resultam na delimitação de parques e áreas de preservação ambiental e da biodiversidade. Muitas dessas medidas são patrocinadas por organizações não governamentais de âmbito mundial, financiadas por corporações e, muito frequentemente, buscam regulamentar as reservas a despeito de conflitos com os povos que nelas vivem, e

(ii) Proposições ecocientificistas que argumentam que é possível corrigir o padrão de acumulação do capital, melhorando a eficiência do uso dos recursos naturais e aperfeiçoando os mecanismos técnicos de controle da contaminação. Se valem de proposições como desenvolvimento sustentável, modernização ecológica e indústrias verdes, validadas por selos de sustentabilidade ambiental. Essas proposições poderiam ser implementadas, na prática, por meio de impostos que levassem em consideração a variável ambiental, o uso de mercados de permissão de emissões e pelo desenvolvimento de tecnologias que economizassem energia e recursos naturais, por meio de formas mais eficientes e complexas de reciclagem: a ideia chave é a mitigação dos efeitos socioambientais da produção capitalista.

A matriz discursiva dessa orientação é o desenvolvimento sustentável que, a rigor, não é um conceito científico, mas, sobretudo, uma ideologia penetrante e indispensável ao capital, em um contexto em que os problemas socioambientais alcançam perigosa escala planetária e as resistências se ampliam. Está fora de questão que a eficiência energética e o controle dos resíduos avançaram de modo extraordinário nas últimas décadas, repercutindo de modo positivo em determinados indicadores ambientais e em certos territórios. Entretanto, é a lógica destrutiva do capital - materializada no desenvolvimento desigual do capital nos territórios - que calibra a forma de consumo de energia, o custo possível das mercadorias e define a escala de circulação das mesmas em âmbito planetário. O exemplo da Articulação Internacional dos Atingidos pela $\mathrm{Val}^{3}$ é significativo. A coordenadora de iniciativas populares existe, justamente, em virtude dos efeitos devastadores provocados pela mineração da Vale em distintas partes do planeta. Produtos sofisticados, ambientalmente certificados, estão inseridos em cadeias produtivas globais, que contém nódulos que requerem despojo de populações e elevado custo socioambiental. $O$ pensamento ambiental eurocêntrico ignora isso.

O desenvolvimento desigual do capitalismo, a circulação ampliada do capital e os processos contratendenciais frente à queda da taxa média de lucros explicam o motivo porque, a despeito dos avanços tecnológicos do pós-II Guerra, os problemas socioambientais agravaram-se de tal modo que a vida no planeta está sob ameaça, conforme os relatórios e pesquisas realizadas no âmbito do Painel Intergovernamental para a Mudança Climática IPCC, na sigla em inglês, e sobretudo pela Conferência Mundial dos Povos sobre o Cambio Climático e os Direitos da Mãe Terra, realizado na Bolívia, em 2010.

As perspectivas culto à vida silvestre e ecocientificista claramente orientaram a divisão do IBAMA, em 2007: O ICMBio ficaria com as unidades de conservação e centros de pesquisa (culto à vida silvestre), enquanto o IBAMA, expurgado da conservação da natureza poderia azeitar as licenças ambientais para as grandes obras, a partir de certas normas tecnocientíficas (ecocientificismo). Com efeito, o orçamento do ICMBio é ínfimo, seu número de trabalhadores irrisório, considerando que o conjunto das áreas de conservação totaliza cerca de $9 \%$ do território do país. A combinação de baixo orçamento e falta severa de pessoal constrange as unidades a buscarem parcerias público-privadas que, em última instância, carreiam as verbas públicas para fins privados. Por sua vez, os licenciamentos do

\footnotetext{
${ }^{2}$ Para um aprofundamento do debate conceitual, sugiro o livro editado por Maristella Svampa e Mirta A. Antonelli, Minería transnacional, narrativas deldesarrollo y resistenciassociales. Bs.As. Editorial Biblos, 2009.

${ }^{3}$ https://atingidospelavale.wordpress.com/quem-somos/.
} 
IBAMA (considerados aqui no total, incluindo licenças prévias, renovações etc.), muitos deles emitidos contra os pareceres técnicos (com se depreende das controvérsias em Belo Monte), cresceram acentuadamente desde então: 2006, 313; 2007, 388; 2008, 525; 2009, 546; 2010, $518 ; 2011,623 ; 2012,707 ; 2013,834 ; 2014,813$ e, já no contexto das denúncias contra as empreiteiras, na operação Lava a Jato, em 2015, 663 licenciamentos. Ou seja, desde o desmembramento, os números mais do que duplicaram (HOFMANN, 2016).

A legislação sobre a educação ambiental foi erigida com resistências, lutas, avanços e retrocessos. É inegável a presença das vozes dos que compreendem que a educação ambiental emancipatória é indissociável da crítica ao modo de produção capitalista; mas, o exame fino da legislação, conforme as pesquisas feitas pelo Laboratório de Investigação em Educação, Ambiente e Sociedade -LIEAS da Universidade Federal do Rio de Janeiro e por seus interlocutores, demonstram que os marcos legais que regem a educação ambiental são prósistêmicos, o que não significa, por suposto, que sejam irrelevantes (longe disso!) e que não devam ser reivindicados nas lutas táticas. Mas os seus limites são epistemológicos, repercutindo na produção de conhecimento novo.

Com efeito, nas medidas de mitigação dos problemas socioambientais, as ações de educação ambiental são convocadas para provocar o encontro harmonioso entre os "cidadãos" expropriados e os grandes empreendimentos econômicos. As resistências verificadas no IBAMA e no ICMBio são trincheiras e ações localizadas que provocam correções, ajustes, revisões, mudanças de rota de gasodutos, indenização a pescadores e outros atingidos. Entretanto, as medidas de educação ambiental exigidas pelo órgão fiscalizador, ainda que a favor das populações afetadas, são efetivadas, via de regra, por parcerias público-privadas com organizações que, contraditoriamente, dependem do financiamento da empresa que o órgão público está interpelando. As tensões são inevitáveis, visto que o setor público exige a mitigação dos efeitos das ações provocadas pela empresa que financiará o programa de educação ambiental. É uma relação que, a despeito da correção, ética e disposição crítica da ONG (ou mesmo do grupo universitário), torna o futuro do trabalho crítico incerto e vulnerável às pressões mais ou menos sutis das empresas. Ademais, como é possível constatar nos grandes empreendimentos, essas medidas corretivas são rapidamente internalizadas nos custos dos produtos e serviços ou, então, têm seus cursos absorvidos pelo Estado, em nome da preservação ambiental. No cômputo geral, é um ambiente inóspito para vicejar o pensamento crítico, passível de ser adensado teoricamente e sistematizado.

De fato, a educação ambiental crítica não pode ser nutrida teórica e politicamente, de modo endógeno, no âmbito do Estado. O emaranhado de leis, normas, portarias etc. e, objetivamente, os interesses das classes possuidoras que operam o padrão de acumulação que David Harvey (2010) denominou como por despossessão, padrão de acumulação conceituado por Florestan Fernandes (1968) como capitalismo dependente, fazem com que a resultante da formulação do Estado sobreponha os interesses das corporações que atuam no setor de commodities aos reclamos socioambientais. O Estado é um garantidor e operador das ferozes expropriações e da brutal exploração do trabalho, que lastreiam o setor de commodities no capitalismo dependente e não reconhece os direitos dos sujeitos que têm suas vidas destroçadas pelos empreendimentos. Novamente, o caso da Samarco é exemplar; a interrupção da reforma agrária, desde o início do primeiro governo Dilma, igualmente corrobora essa proposição.

Se a educação ambiental crítica encontra dificuldade de se desenvolver, teórica e praticamente, nos conflitos advindos do processo de licenciamento de grandes empreendimentos, é necessário indagar se nas escolas públicas está sendo possível tal adensamento teórico-prático. Um exame dos programas governamentais, parcerias com empresas, experiências escolares e de formação docente, confirma que a perspectiva crítica se desenvolve em um ambiente educacional francamente hostil. Com efeito, a incorporação, nas 
diversas esferas do Estado, da agenda empresarial veiculada pelo Todos pela Educação, pela coalizão ultraconservadora Escola Sem Partido, pelas entidades sindicais patronais (Sistema S), pelas corporações (Vale S.A., Gerdau...) e pelas entidades empresariais do agronegócio (Associação Brasileira do Agronegócio), torna quase que estéril o solo para vicejar a educação ambiental inscrita na perspectiva histórico-crítica e libertária. O controle do capital sobre a educação básica busca pasteurizar, por meio de seu moinho triturador, todas as práticas educativas críticas nas escolas.

Medidas como avaliações de desempenho elaboradas a partir de descritores desprovidos de relevância científica, cumprimento de metas, ranqueamento das escolas, convênios com empresas e mesmo a presença direta das empresas nas escolas tornam, objetivamente, o trabalho pedagógico crítico um gesto de rebeldia, localizado, imerso em um contexto francamente inóspito. Com a educação ambiental não poderia ser diferente. Definida como tema transversal nos parâmetros curriculares, a educação ambiental sequer é considerada nas avaliações que irão decidir o futuro da escola, tornando-a acessória e pouco relevante, a exemplo da arte, da cultura e do conhecimento histórico-crítico da natureza e da sociedade. Contraditoriamente, a não consideração da mesma no sistema de avaliação permite ações críticas em polos democráticos da sociedade civil. E tais nichos estão em conexão com os conflitos socioambientais.

Ademais, em virtude da presença de movimentos sociais que reivindicam a perspectiva crítica, os intelectuais do capital chegam a se valer até mesmo do léxico pósmoderno para assimilar e esvaziar as proposições emancipatórias de seus sentidos anticapitalistas produzidos nas lutas de classes. É necessário, por conseguinte, dialogar com a produção do conhecimento decorrente das lutas contra o despojo e de seus nexos com espaços de produção de conhecimento científico referenciado em uma ética pública.

\section{A vertente crítica ao sociometabolismo do capital}

Pelo exposto, é imperativo examinar a questão socioambiental de um outro prisma, a partir de um outro ponto de vista, de outros lugares e de outras referências. Esse é o sentido da segunda vertente da educação ambiental, surgida nas lutas e nas resistências dos trabalhadores, camponeses, povos originários e favelados que, ao defenderem seus territórios, produzem conhecimento a partir de outras perspectivas teóricas, epistemológicas e políticas, expressas nas lutas contra as expropriações, em defesa de Nossa América e do Bem-Viver, conforme sínteses encontradas na CLOC-Via Campesina, no MST, nas lutas indígenas e nas resistências contra as mineradoras e o agronegócio, nas jornadas contra o saqueio das reservas aquíferas, a abertura de corredores econômicos a partir de rodovias, ferrovias e hidrovias (IIRSA- COSIPLAN, Plano Puebla-Panamá) e, não menos importante, nos processos de formação dentro e fora das instituições educacionais. Nesses espaços a crítica ao padrão de acumulação, ao neodesenvolvimentismo e aos grandes eixos econômicos do IIRSACOSIPLAN, caracteriza o chamado desenvolvimento sustentável e a economia verde no rol das ideologias e proposições econômicas dominantes, ainda que, frequentemente, sem utilizar os termos consagrados no léxico ambiental.

Como destacado por Loureiro (2015), essa perspectiva possui convergência com o movimento por justiça ambiental, em defesa dos bens comuns. O foco, aqui, são os conflitos socioambientais provocados pelo padrão de acumulação do capital, pela nova geografia econômica mundial, que redefine os termos do desenvolvimento desigual e combinado do capitalismo. Importa examinar a forma específica de articulação e subordinação das frações burguesas locais com as frações hegemônicas, a força do núcleo mais dinâmico do capital, impulsionado pelo setor financeiro e pelas megacorporações que determinam preços, 
quantidades e fluxos das mercadorias, calibrando, desse modo, a intensidade das expropriações e da exploração do trabalho.

No Brasil, os novos marcos da problemática socioambiental foram forjados pelo setor financeiro, em especial a partir da Crise da Dívida de 1982, quando o modelo de industrialização ancorado pelo Estado, por grandes grupos nacionais e multinacionais, induzidos por medidas fortemente protecionistas, por pesados subsídios públicos, deixou de ser funcional ao capitalismo monopolista, em crise desde os anos 1970. Como medida para saída da crise, as políticas do Consenso de Washington, os pilares do chamado neoliberalismo, reconfiguraram em profundidade a economia latino-americana, objetivando assegurar as condições macro e microeconômicas que viabilizassem o pagamento dos juros e serviços da dívida externa que, nas décadas de 1960 e 1970, havia lastreado o chamado milagre econômico brasileiro. A taxa de juros conheceu uma trajetória de crescimento tão acentuada que não seria exagero afirmar que países como Argentina, Brasil e México foram submetidos à agiotagem da banca internacional (MILLET; TOUSSAINT, 2006).

Uma combinação de medidas alterou em profundidade a economia brasileira: abertura econômica; privatizações de empresas públicas como a Vale do Rio Doce (agora Vale S.A.) e a Companhia Siderúrgica Nacional; flexibilização laboral, desregulamentação de diversas relações econômicas, em suma, o lugar do Estado implementado pela ditadura foi redefinido. Objetivando fortalecer a captação de dólares, nos anos 1980 e 1990, um novo impulso foi conferido ao setor de exportação de commodities, referenciado na tese das vantagens comparativas da economia latino-americana. O novo lugar da China na economia mundial, com o deslocamento de grande parte do setor industrial dos EUA para esse país, tornou a potência oriental uma voraz compradora de commodities e as frações burguesas que operam no Brasil adaptaram a economia a essa relação de subordinação. A reconfiguração do Brasil como produtor de commodities para atender às necessidades chinesas teve seu apogeu nos governos de Lula da Silva, que não hesitou em aprofundar a referida subordinação da economia brasileira às necessidades econômicas da nova potência. Conforme dados da Comunidade dos Estados Latino-Americanos e Caribenhos, em 2000, as transações do Brasil com a China alcançaram US\$ 12,6 bilhões e, em 2014, alcançaram impressionantes US\$ 240 bilhões, tornando a China a maior parceira econômica do Brasil. O que isso significa para a problemática socioambiental?

Conforme os indicadores apresentados por Accioly (2015), as exportações por fator agregado vêm alternando velozmente o perfil econômico do país. Com efeito, em 2004 os manufaturados corresponderam a 55\% das exportações e, em 2013, o setor despencou para modestos $38,4 \%$, indicando uma radical mudança na base produtiva. O inverso aconteceu com os produtos básicos (primários): 2000, 29,5\% e, em 2013, 46,7\%. Se pode ser controverso falar em desindustrialização, é forçoso reconhecer que a exportação de commodities foi convertida no carro chefe da economia, visto que, além da exportação de produtos brutos, primários, muito dos produtos semimanufaturados e manufaturados são intensivos em recursos naturais e foram manufaturados por meio de tecnologias intermediárias, afastando o país da economia mundial de produtos e serviços de maior complexidade.

Voltando, agora, à pergunta anterior: as consequências socioambientais são evidentes, pois esse verdadeiro saqueio dos recursos naturais é indissociável das expropriações que, por sua vez, adensam os conflitos socioambientais no Brasil, na América Latina, na África e em grande parte da Ásia. Em outros termos: as frações burguesas locais, seus sócios majoritários nos países hegemônicos e os governos que manejam o Estado (como se depreende do BNDES, do novo Código Florestal, do desmembramento do IBAMA etc.) aprofundam o capitalismo dependente, isto é, as expropriações e a exploração. Os conflitos socioambientais, portanto, estão no olho do furação do capitalismo ultramoderno, que coexiste com formas bárbaras e arcaicas de extração de mais-valia. 
No plano epistemológico, a nova realidade da problemática socioambiental somente pode ser compreendida, em sua radicalidade, a partir do diálogo verdadeiro, horizontalizado, com os sujeitos que empreendem as lutas de resistências. O significado do desenvolvimento sustentável pode ser objeto de seminários acadêmicos infindáveis. A arma da crítica é crucial, mas a ideologia do desenvolvimento sustentável somente será plenamente compreendida (e enfrentada!) se as lutas forem consideradas na perspectiva dos - e com os - sujeitos que as protagonizam. Não se trata, aqui, de idealizar ou sacralizar os sujeitos que empreendem as lutas individualmente, mas de captar as organizações coletivas, os movimentos, as coordenadoras das lutas que estão enfrentando a ideologia da sustentabilidade.

Um salto de qualidade crucial foi a constituição da Coordenadora Latino-Americana de Organizações do Campo (CLOC), em 1994 que, mais tarde, passou a atuar em conjunto com a Via Campesina. Outras iniciativas, mais localizadas, foram erigidas em todos os países da região com destaque para a Coordenadora Andina de Organizações Indígenas (CAOI), em 2006. Essas lutas alcançaram as cidades, forjando novas relações entre movimentos sociais, sindicatos, partidos de esquerda, como na Guerra da Água, em Cochabamba, 2000; na Guerra do Gás (2003), na Bolívia, e a resistência ao golpe contra Chávez, em 2002, na Venezuela. Diante do retrocesso da Conferência de Copenhague sobre a mudança climática e dos intentos de retroceder até mesmo o Protocolo de Kyoto, os movimentos sociais e o governo da Bolívia convocaram, em 2010, a citada Conferência Mundial dos Povos sobre o Cambio Climático e os Direitos da Mãe Terra, sinalizando que a agenda em prol dos povos, unitária e popular, não pode estar aprisionada pelos interesses dos setores dominantes que, por meio dos Estados, obstaculizam as conferências oficiais.

As diversas produções elaboradas por esses movimentos evidenciaram que não se tratava do velho saqueio colonial, mas de um neoextrativismo (que inclui novos recursos, como a água, a biodiversidade/ biotecnologias, o turismo, as novas configurações do agronegócio) sob o comando do capital financeiro que moveu seus centros de pensamento para produzir ideologias que justificassem o extrativismo no século XXI, como economia verde, desenvolvimento sustentável etc. Reforçando e dando novo sentido ao prefixo neo, esse extrativismo de novo tipo, operacionalizado por grandes grupos econômicos, bancos, organismos internacionais, como o Banco Mundial, foi ressignificado como parte da agenda dita pós-neoliberal ou neodesenvolvimentista por governos considerados progressistas, como Lula e Dilma no Brasil, o casal Kirchner na Argentina, Bachelet, no Chile, Tabaré e Mujica no Uruguai, Morález, na Bolívia, Correa, no Equador etc.

Não é propósito deste texto esboçar uma resposta a tão complexa questão. Uma hipótese explicativa para a adesão do chamado novo progressismo da América Latina ao modelo extrativista é que esses governos foram constituídos ou tolerados pelos setores dominantes em virtude do agravamento da crise que se adensou em 1998, crise que levou à destituição de perto de uma dúzia de governos neoliberais na América Latina. Em nome da estabilidade política, frações financeiras apoiaram ou incentivaram esses governos por avaliarem que, como tinham ascendência sobre sindicatos e movimentos sociais, governos com perfil social poderiam robustecer a governabilidade para o capital. Mas o apoio do bloco de poder continha uma condição básica: a manutenção dos fundamentos macroeconômicos desejados pelo grande capital, concedendo autonomia ao Banco Central e fortalecendo o setor exportador, injetando volumosos recursos para as grandes empresas do setor via BNDES, para que os juros seguissem sendo pagos (no Brasil foi este o teor da conhecida Carta aos Brasileiros, 2002). Os governos progressistas, por sua vez, viram na valorização das commodities, impulsionada pela China, a oportunidade de conjugar o pagamento do serviço e juros da dívida e, no rastro do crescimento econômico, ampliar o gotejamento de recursos para políticas focalizadas nos pobres, assegurando, ao mesmo tempo, governabilidade e apoio dos pobres e dos novos consumidores, a dita classe $\mathrm{C}$, ao governo em futuras eleições. Desde 
então, esses governos compreenderam que essa era a via possível, ainda que tal opção provocasse conflitos com parte de seus antigos aliados, inclusive atritos que acabaram sendo criminalizados. Em geral, os governos neodesenvolvimentistas não viram nesses conflitos uma situação politicamente preocupante, por acreditarem em sua influência sobre suas direções e porque dificilmente se voltariam contra o governo em momentos de disputa eleitoral com os antigos neoliberais, visto que estes sempre serão vistos como um inimigo mais deletério. No Brasil, os multitudinários protestos de 2013 indicaram que esse controle já não era efetivo, abrindo um campo de disputa no qual os setores conservadores mostraram surpreendente capacidade de iniciativa e de convocação.

Se a hipótese for razoável, é possível postular que, com os governos progressistas, haveria, durante um certo tempo, um refluxo da luta de classes protagonizada pelos assalariados. Se no setor industrial e nos serviços privados isso ocorreu (as greves foram muito reduzidas nos dois mandatos de Lula, por exemplo), de outra parte, os sujeitos sociais que o pensamento marxista evolucionista e mecanicista avaliava como fadados ao desaparecimento emergiram com extraordinária impetuosidade na América Latina, como os povos originários, camponeses e trabalhadores do campo. No caso das lutas urbanas, o balanço das greves dos setores público e privado, confirma que, nesse período, prevaleceram amplamente as lutas do setor público, nas quais os trabalhadores da educação tiveram grande protagonismo. Somente a partir do agravamento da crise, em 2012, é que o setor privado tem tido predominância (DIEESE, 2015).

No período de hipervalorização das commodities, o enfrentamento ao neodesenvolvimentismo foi quase que monopolizado pelos sujeitos que foram expropriados no campo (e, de modo difuso, nas cidades) e por setores do funcionalismo público. Isso poderia explicar a extraordinária movimentação desses sujeitos e o arejamento intelectual por eles proporcionado, contribuindo para a renovação do pensamento crítico. É possível esboçar a hipótese de que, com o agravamento da crise estrutural, afetando a economia chinesa, resultando na queda dos preços das commodities, a intensidade das expropriações venha a ser alterada. A extinção do Ministério do Desenvolvimento Agrário, pelo governo interino de Michel Temer, sinaliza a tendência.

No contexto de agravamento da crise econômica, também os setores dominantes se moveram. Como o transformismo desorganizou a classe trabalhadora, diversas frações burguesas dominantes se viram encorajadas a perseguir o objetivo de recompor a taxa de lucros encolhida pela crise, por meio de contrarreformas, como: trabalhista, previdenciária, a extinção de loci do Estado voltados para a questão agrária, a flexibilização, ainda maior, da legislação ambiental, como a PEC 65/2012, em tramitação no Senado (julho de 2016) que acrescenta o $\S 7^{\circ}$ ao art. 225 da Constituição Federal que dispõe que a apresentação do estudo prévio de impacto ambiental importa autorização para a execução da obra, que não poderá ser suspensa ou cancelada pelas mesmas razões a não ser em face de fato superveniente (BRASIL, 2012a), a mercantilização da saúde e da educação, envolvendo mudanças constitucionais para assegurar maior permanência a essas medidas. Nesse escopo, mudanças de governos passam a ser perseguidas, de modo legítimo ou não, como se depreende das crises políticas no Brasil, Argentina, Venezuela, Equador etc. - justo os governos progressistas.

No rastro da crise, é necessário colocar em relevo os conflitos protagonizados pelos trabalhadores precarizados nas cidades, insatisfeitos com o aumento do desemprego real, o acentuado endividamento, a degradação nos transportes e a perda de poder aquisitivo (SEOANE; TADDEI; ALGRANATI, 2013). De fato, também nas cidades e nas periferias, a crise estrutural passa a ser enfrentada por sujeitos que até então não haviam se manifestado no espaço público, como o precariado a que se refere Braga (2014) (melhor caracterizado como 
a fração mais precarizada do proletariado) e que tiveram notável destaque nas Jornadas de Junho de 2013.

Com o transformismo dos setores mais organizados da classe trabalhadora, também a direita fundamentalista entra em cena no Brasil, em defesa de valores morais de cunho religioso e fortemente pró-sistêmica no plano econômico, alinhada ao bloco de poder em recomposição e, por conseguinte, neoliberal no que tange à problemática ambiental. Assim, de um lado, a presença desses protagonistas nas lutas contra as remoções advindas da cidademercadoria e o custo do transporte de péssima qualidade, pode engendrar novas dimensões para a problemática socioambiental, como o saneamento, a mobilidade urbana, o enfrentamento das remoções forçadas, e os danos ambientais que afetam as áreas populares etc. e, de outro, em seus interstícios difunde uma agenda profundamente conservadora, notadamente na educação, a exemplo de iniciativas como a Escola Sem Partido, que colide abertamente com a educação ambiental crítica.

\section{Bases epistêmicas e epistemológicas forjadas nas lutas}

Um importante aprendizado advindo das lutas na América Latina é o peso da nova geografia econômica. É necessário conhecer e acompanhar o deslocamento geográfico dos recursos naturais: onde, por quem, com que participação do Estado, para onde, em benefício de que setores, são indagações imprescindíveis que somente podem ser plenamente conhecidas a partir das resistências e das lutas. O acompanhamento dos Atingidos pelas Barragens; dos povos que resistem a Belo Monte; dos camponeses que resistem em ceder a bacia aquífera Guarani para as papeleras; das lutas contra os atingidos pela Vale; da luta contra as mineradoras a céu aberto na Patagônia; das resistências contra a rodovia financiada pelo BNDES que corta os territórios indígenas na Bolívia (Tipnis), em direção ao Pacífico, corroborando a efetivação da Aliança do Pacífico liderada pelos EUA; da Marcha Nacional pela Água no Peru contra o projeto de expansão das mineradoras em Cajamarca (2012); das lutas no Equador contra a megamineração; das lutas camponesas no Paraguai contra a expansão da soja, entre outros tantos exemplos, permitem compreender o novo mapa geoestratégico da região. Nesse mapa, além dos movimentos, recursos naturais, rodovias, hidrelétricas etc., é possível identificar as bases militares nacionais e estrangeiras, as doutrinas de segurança, as corporações, as zonas de incentivo fiscal e a localização e o perfil das instituições de ensino.

As bases empíricas para esse novo mapa geoestratégico podem ser encontradas nas diversas produções dos movimentos sociais, como nos estudos, nos documentos, nos manifestos, nas declarações de encontros que adensam e renovam o pensamento crítico socioambiental, atualizando ainda um tema que parecia guardado na última gaveta das antiguidades ideológicas, $o$ internacionalismo, tema crucial no momento em que em todo mundo os movimentos proletários avaliam o significado da criação da Associação Internacional dos Trabalhadores.

Nas lutas contra as expropriações, a formulação original de Chico Mendes provocou um verdadeiro choque teórico ao propugnar uma nova forma de reforma agrária coletivista, por meio das reservas extrativistas, tema que motivou uma importante tese de doutorado desenvolvida no LIEAS, de autoria de Cunha (2010).

O uso comum dos recursos naturais, um anátema no capitalismo, é também sustentado pela Minga Global (Kechwa = ação coletiva) e pelo Bem-Viver: os saberes ancestrais, a cosmovisão, a Mãe Terra, as lutas antissistêmicas, são fundamentais para a compreensão da totalidade concreta, por meio de suas determinações contradições, em oposição ao idealismo holista: "recorremos às nossas raízes para projetarmos o futuro com nossos princípios e práticas de equilíbrio entre homens, mulheres, Mãe Terra, espiritualidades, culturas, povos, que denominamos de Bem-Viver" ( DECLARACIÓN DE LOS PUEBLOS INDÍGENAS DEL MUNDO, 2010, p.1). 
O I Encontro sobre Cosmovisão e Identidade dos Povos Originários e Afrodescendentes CLOC-Via Campesina (2011, p.4) declara: "condenamos o capitalismo [exploração dos recursos naturais e da força de trabalho], o Bem Viver é incompatível com o capitalismo". O II Encontro Continental de Formadores/as Agroecológicos CLOC-Via Campesina, 2011, explicita:

Múltiplas crises decorrem do capitalismo. Dominação do capital sobre a produção de bens da natureza, crise alimentar, crise energética, crise climática. A exportação de commodities é decisiva para o capitalismo em crise. O capital nacional e transnacional tem avançado sobre os territórios. Governos da região são operadores desse modelo. Difundem assistência social que ajuda em momentos de emergência, porém introduzem uma lógica paternalista e conformista (CLOC-VC, 2011, p.1-2).

Distintamente das narrativas pós-modernas, o II Encontro "defende os saberes e a epistemologia dos povos em articulação com o materialismo histórico e dialético". Sustentam o enlace cosmovisão - materialismo histórico. Segue a declaração: "A formação político ideológica tem de ser realizada para fazer luta de classes". O documento explicita o arco de forças: "indígenas, camponeses, operários, estar nas lutas dos povos!" (CLOC-VP, 2011, p. 23)

Essa perspectiva teórica, ética, epistemológica, pode ser encontrada em iniciativas como o Juicio Ético a las Transnacionales". Sentencia del Juicio ético y popular a las transnacionales, Audiencia de la Triple Frontera (2011). Nesse documento, é possível encontrar original crítica aos fundamentos do modelo neoextrativista, por meio de proposições fortes, como: "Hay en curso un ecocidio y un genocidio silenciosos", "Como parte de la recolonización de nuestro continente se nos ha impuesto un modelo agroalimentario hegemónico, en el que la alimentación transformada en mercancía es un mecanismo de control de nuestras vidas por parte de las grandes corporaciones transnacionales" [...], denuncia "la alta concentración de las tierras", "el control de las semillas y de los plaguicidas asociados a ellas", "el saqueo de los bienes comunes", o "agravamiento del cambio climático", a "desertificación y pérdida de fertilidad de los suelos", o "éxodo y expulsión rural, por el desplazamiento de comunidades", a "alteración de las formas de vida de los pueblos, desconocimiento de sus usos y costumbres y negación de sus identidades", a "criminalización de movimientos sociales y de comunidades", a "generación de pobreza, reducción de empleo, precarización y flexibilización laboral en los trabajos realizados en estas empresas, aumento del trabajo temporario, tercerización del empleo y utilización de trabajo esclavo", a "destrucción de la agricultura campesina: las comunidades campesinas e indígenas son impedidas de desarrollar sus formas tradicionales de cultivo, ante el avance del modelo de agricultura industrial", o "patentamiento de plantas y saberes asociados a ellas. Las empresas transnacionales son responsables de biopiratería, del robo y la apropiación de los saberes de los pueblos" (TRIBUNAL..., 2011, p.12).

As lutas dos tribunais populares não deixaram de identificar a responsabilidade de universidades que são financiadas por corporações e acabam abandonando qualquer perspectiva ética na produção do conhecimento. Cabe destacar um excerto da sentença final do Tribunal (2011, p. 12-13)

La complicidad de algunas universidades públicas con las empresas transnacionales se constata en el comportamiento que desempeñan las primeras, en relación a ocultar, tergiversar o producir conocimiento científico o informes técnicos que favorecen a las empresas, manipulando, en muchas ocasiones, los resultados de los Estudios de Impacto Ambiental en sentido favorable a los intereses transnacionales.

Segue a sentença:

Este tribunal ha constatado que este mecanismo genera un proceso de colonización de la producción de conocimientos científicos por parte de intereses privados, 
muchas veces transnacionales. Merece destacarse como ejemplo, el premio "Animarse a emprender", convocado, en 2006, por Monsanto Argentina y el CONICET (Consejo Nacional de Investigaciones Científicas y Técnicas), que tuvo como objetivo premiar el mejor proyecto tecnológico en el área de cultivos nativos de importancia regional para el país. Otro ejemplo presentado en este juicio se refiere a los convenios que la Universidad Nacional de Lomas de Zamora tiene con la transnacional Monsanto para realizar investigaciones científicas solicitadas por la empresa en la Facultad de Ciencias Agrarias. El compromiso de la Universidad asumido en la firma del convenio es, según datos aportados por la fiscalía de esta transnacional, "no copiar, comunicar, distribuir, diseminar, exponer o, de cualquier otro modo, revelar la información confidencial" que resulte de los estudios y proyectos de investigación que realiza para Monsanto. Se obliga, además -según señala expresamente el convenio, a realizar trabajos de asesoría y consultoría, investigación y desarrollo y a mucho más: "colaborar en la ejecución de trabajos de Tesis de Grado o Posgrado por alumnos de la Facultad en temas de interés para ambas partes". Este convenio demuestra claramente la forma en que los contenidos y objetivos académicos se ponen al servicio de los intereses de las corporaciones (TRIBUNAL..., 2011, grifos do original).

O discurso e os interesses empresariais foram aninhados na questão ambiental e, mais especialmente, na educação ambiental. A formulação ideológica hegemônica está sendo entranhada no próprio léxico ambiental em que a perspectivas socioambiental e históricocrítica são desconsideradas e mesmo abertamente criticadas por se confrontarem com o pensamento dominante.

Por tudo isso, os debates estratégicos, epistemológicos e teóricos sobre as resistências e, igualmente importante, pois parte do mesmo processo, para as reflexões das proposições alternativas que as lutas socioambientais, dentro e fora da escola e das universidades, são cruciais para enfrentar a barbárie do novo ciclo capitalista dependente, potencializada pelas mudanças extraconstitucionais no Brasil, em 2016.

\section{Referências}

ACCIOLY, I. Ideologia do desenvolvimento e do consumo sustentável na educação ambiental: uma análise das políticas públicas na Década da Educação para o Desenvolvimento Sustentável. In LAMOSA, R.; LOUREIRO, C.F.B. (Orgs.). Educação Ambiental no Contexto Escolar: um balanço crítico da década da Educação para o Desenvolvimento Sustentável. Rio de Janeiro: Quartet/CNPq, 2015. p.68-104.

BRAGA, R. Cenedic: uma sociologia à altura de Junho. Portal da Editora Boitempo [Online, 2014]. Disponível em: <http://blogdaboitempo.com.br/category/ colunas/ ruy-braga/>. Acesso em: 18 ago. 2016.

BRASIL. Lei 12.334, 20 de setembro de 2010, Estabelece a Política Nacional de Segurança de Barragens destinadas à acumulação de água para quaisquer usos, à disposição final ou temporária de rejeitos e à acumulação de resíduos industriais, cria o Sistema Nacional de Informações sobre Segurança de Barragens e altera a redação do art. 35 da Lei no 9.433, de 8 de janeiro de 1997, e do art. 4ㅇ da Lei no9.984, de 17 de julho de 2000, disponível em http://www.planalto.gov.br/ccivil_03/_Ato2007-2010/2010/Lei/L12334.htm.

BRASIL. Lei 12.651, 25 de maio de 2012, Dispõe sobre a proteção da vegetação nativa; altera as Leis nos 6.938, de 31 de agosto de 1981, 9.393, de 19 de dezembro de 1996, e 11.428, de 22 de dezembro de 2006; revoga as Leis nos 4.771, de 15 de setembro de 1965, e 7.754, de 14 de abril de 1989, e a Medida Provisória no 2.166-67, de 24 de agosto de 2001; e dá outras providências. Disponível em http://www.planalto.gov.br/ccivil_03/_ato2011-2014/2012/lei/112651.htm 
BRASIL. Senado Federal. PROPOSTA DE EMENDA À CONSTITUIÇÃO no 65, de 2012. Acrescenta o $\S 7^{\circ}$ ao art. 225 da Constituição, para assegurar a continuidade de obra pública após a concessão da licença ambiental. Disponível em: https://www25.senado.leg.br/web/atividade/materias//materia/109736

BRASIL. Câmara dos Deputados, Projeto de Lei 5807, 2013, Dispõe sobre a atividade de mineração, cria o Conselho Nacional de Política Mineral e a Agência Nacional de Mineração - ANM, e dá outras providências. $\quad$ Disponível em: http://www.camara.gov.br/proposicoesWeb/fichadetramitacao?idProposicao=581696

CLOC-VIA CAMPESINA. Encuentro Continental Americano de Formadoras y Formadores Agroecológicos, CLOC - Vía Campesina, Chimaltenango, Guatemala, 03 de agosto del 2011. Disponível em: https://viacampesina.org/es/index.php/temas-principales-mainmenu-27/agriculturacampesina-sostenible-mainmenu-42/1218-ii-encuentro-continental-de-formadoras-y-formadoresagroecologicos, acesso em 12 de agosto de 2016.

CUNHA, C. C. Reservas extrativistas: institucionalização e implementação no Estado brasileiro dos anos 1990. 2010, 308 p. Tese (Doutorado em Psicossociologia de Comunidades e Ecologia Social, Programa de Pós-Graduação em Psicossociologia de Comunidades e Ecologia Social - EICOS), Universidade Federal do Rio de Janeiro, 2010.

DECLARACIÓN DE LOS PUEBLOS INDÍGENAS DEL MUNDO, 2010, Conferencia Mundial de los Pueblos sobre el Cambio Climático y los Derechos de la Madre Tierra, del 19 al 22 de Abril del año 2010 en Tiquipaya, Cochabamba, Bolívia. Disponível em: http://www.pueblosoriginariosenamerica.org/?q=book/export/html/99, acesso em 15 de julho de 2016.

DEPARTAMENTO INTERSINDICAL DE ESTATÍSTICA E ESTUDOS SOCIOECONÔMICOS DIEESE. Balanço das greves de 2013. Estudos e Pesquisas, São Paulo, n. 79, p. 1-44, Dez. 2015.

DECLARACIÓN FINAL DEL I ENCUENTRO SOBRE COSMOVISIÓN E IDENTIDAD DE LOS PUEBLOS ORIGINARIOS Y AFRODESCENDENTES, 2011, San Lucas Sacatepéquez, Guatemala. 23 de agosto de 2011. Enlace Indígena, disponível em: http://movimientos.org/es/enlacei/show_text.php3\%3Fkey\%3D19717, acesso em 10 de junho de 2016.

ENGELS, F. Para a história da Liga dos Comunistas (1885). In: Obras Escolhidas. BARATAMOURA, J.; CHITAS, E.; MELO, F.; PINA, A. (Coord.). Moscovo: Editorial Avante!, 1982. Tomo III, p. 192-212.

FERNANDES, F. Sociedade de classes e subdesenvolvimento. Rio de Janeiro: Zahar, 1968.

HARVEY, D. O novo imperialismo. 4 ed. Tradução de SOBRAL e GONÇALVES. São Paulo: Loyola, 2010.

HOFMANN, R. M. Gargalos do Licenciamento Ambiental Federal no Brasil. In: $1^{\circ}$ SEMINÁRIO INTERNACIONAL SOBRE LICENCIAMENTO AMBIENTAL E GOVERNANÇA TERRITORIAL, 2016, Brasília. Anais... Brasília: Ipea/IPC-IG/Swedish EPA, 2016. p.1-21. Disponível em: <http://www.ipea.gov.br/agencia/images/stories/PDFs/20160314_gargalosdolicenciamentoambientalfe deralnobrasil.pdf>. Acesso em: 18 ago. 2016.

LEHER, R. Neodesenvolvimentismo e pós-neoliberalismo como narrativas dominantes da crise capitalista. MACÁRIO, E.; VALE, E. S. do.; RODRIGUES JUNIOR, N. dos S. (Orgs.) Neodesenvolvimentismo, trabalho e questão social, Fortaleza: UECE, Expressão Gráfica Editora, 2016. 
LOUREIRO, C. F. B. Educação ambiental e educação para o desenvolvimento sustentável: polêmicas, aproximações e distanciamentos. In LAMOSA, R.; LOUREIRO, C.F.B. (Orgs.). Educação Ambiental no Contexto Escolar: um balanço crítico da década da Educação para o Desenvolvimento Sustentável. Rio de Janeiro: Quartet/CNPq, 2015. p.35-67.

MILLET, D.; TOUSSAINT, É. 50 perguntas e respostas sobre a dívida, o FMI e o Banco Mundial. São Paulo: Boitempo, 2006.

SEOANE, J.; TADDEI, E.; ALGRANATI, C. Extractivismo, despojo y crisis climática. Buenos Aires: Herramienta/Editorial El Colectivo, 2013.

TRIBUNAL DEL JUICIO ETICO. Proceso de justicia popular contra las estrategias neocoloniales en Nuestra América [Online]. Disponível em: <http://juicioalastransnacionales.org/2011/11/sentenciafinal-del-tribunal-del-juicio-etico-a-las-transnacionales/>. Acesso em: 18 ago. 2016. 